WellBeing International

WBI Studies Repository

$5-1991$

\title{
Effect of Straw on the Behaviour of Growing Pigs
}

David Fraser

Agriculture Canada

P. A. Phillips

Agriculture Canada

B. K. Thompson

Agriculture Canada

T. Tennessen

Agriculture Canada

Follow this and additional works at: https://www.wellbeingintlstudiesrepository.org/socbeh

Part of the Animal Studies Commons, Behavior and Ethology Commons, and the Comparative Psychology Commons

\section{Recommended Citation}

Fraser, D., Phillips, P. A., Thompson, B. K., \& Tennessen, T. (1991). Effect of straw on the behaviour of growing pigs. Applied Animal Behaviour Science, 30(3-4), 307-318.

This material is brought to you for free and open access by WellBeing International. It has been accepted for inclusion by an authorized administrator of the WBI Studies Repository. For more information, please contact wbisr-info@wellbeingintl.org.

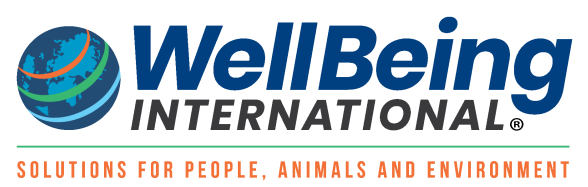




\title{
Effect of Straw on the Behaviour of Growing Pigs
}

\author{
David Fraser, P.A. Phillips, B.K. Thompson, T. Tennessen
}

Agriculture Canada

\begin{abstract}
The effects of straw on the behaviour of young growing pigs were studied in two experiments. In Experiment 1, group of three pigs, aged about 7 weeks, were housed in raised decks with or without straw bedding. Time-lapse video recording showed no major differences between treatments in the amount or daily pattern of overall activity and feeding. Detailed observations showed that bedding reduced the incidence of rooting and chewing on pen-mates, but had little effect on other social activities such as mounting and aggressive biting. Experiment 2 compared groups of eight growing pigs aged about 10 weeks, housed in floor pens with or without a small amount of straw provided daily in a rack. Pigs with straw concentrated more of their daily activity into the period when straw was fresh, but the total amount of overall activity and time spent feeding were not affected. Rooting and chewing of pen-mates were the only social activities reduced by the provision of fresh straw. In these studies, where straw was not required to compensate for deficiencies such as low temperatures or hunger, the one major function of straw was to provide a stimulus and outlet for rooting and chewing, with a resulting reduction in such activities directed at pen-mates.
\end{abstract}

\section{INTRODUCTION}

The provision of straw is widely considered to be beneficial for the comfort and well-being of pigs (Müller et al., 1979; van Putten, 1980). However, the actual effects of straw are complex and depend greatly on the type of pigs and the conditions under which they are raised (see e.g. Stephens, 1971; Schouten, 1986; Edwards and Furniss, 1988). For closely confined sows on a concrete floor and fed a restricted diet, straw is thought to have three distinct effects: (i) as bedding it improves the thermal comfort and perhaps the physical comfort of the floor; (ii) it is eaten in appreciable amounts and results in greater filling of the gut; (iii) it serves a "recreational" function as a stimulus and outlet for the rooting and chewing activities that are natural to pigs (Fraser, 1975; Sambraus and Schunke, 1982).

The situation is different for younger, growing-finishing pigs. Firstly, because these animals are often fed ad libitum or nearly so, any filling of the gut with straw is of questionable benefit. Secondly, the relationship of straw to floor comfort depends greatly on environmental temperatures: growing pigs prefer to lie on straw under cool conditions, but prefer bare floors at higher temperatures (Fraser, 1985; Marx and Mertz, 1989). This leaves the "recreational" effect of straw as the one major potential benefit that remains when feeding levels and environmental temperature do not create additional needs.

Although several studies have reported apparent effects of straw on the behaviour of growing pigs, the research has generally involved a confounding of straw with other variables. For example, Buré (1981) reported that weaned pigs housed with straw performed less "abnormal" behaviour (tail-biting, rooting, massaging, and nibbling of pen-mates) than pigs reared without straw. However, the study compared 
pigs kept in an unheated barn with straw and pigs kept in "battery cages" without straw but also with much less space allowance per animal. Van Putten and Dammers (1976) reached a similar conclusion in a study that compared weaned pigs in flat-deck cages and pigs of similar age still suckling the sow in large strawed pens. Van Putten (1980) compared pigs reared to market weight in pens with and without small amounts of straw, but the two treatments were applied in different years. Ruiterkamp (1986) compared pigs housed in straw-based or slatted housing, but the pigs on slats were housed with less space and very low illumination levels.

In the experiments described below, we studied the effect of straw on the behaviour of growing pigs housed at comfortable temperatures, with ad libitum feed, and in small uncrowded groups. Our objective was to identify the effects of straw on the pigs' behaviour in conditions where straw was not needed to compensate for an obvious and avoidable deficiency such as hunger or cold. To broaden the applicability of the findings, we conducted two studies using pigs of different ages, housed in different pen types, and with straw presented in two different ways.

\section{ANIMALS, MATERIALS AND METHODS}

\section{Experiment 1}

The first experiment studied young growing pigs, housed in small raised pens with or without deep straw bedding. A randomized block design was used with 60 female and castrated male pigs assigned to two treatments (bedding or no bedding) in ten replicates. Each replicate comprised six pigs, usually littermates, divided into two groups of three animals each, in a manner that made the sex ratio and initial weights as similar as possible between the two groups. One group three pig was then assigned at random to the bedding treatment the other to the no-bedding treatment.

Each group of three pigs was housed in a pen $1.1 \mathrm{~m} \times 1.2 \mathrm{~m}$, with a solid concrete floor raised $0.8 \mathrm{~m}$ above the floor of the room. Pens were enclosed by solid, galvanized metal walls on three sides and a gate of steel spindles on the fourth which allowed the pigs to be observed. In each pen, water was freely available from a nipple drinker and feed from a feeder which allowed two animals to feed simultaneously. Four such pens were located in a small room where a thermostatically controlled heater and air-cooling unit maintained air temperature at $25 \pm 2^{\circ} \mathrm{C}$. As each replicate required one pen with straw and one without, the four pens allowed two replicates to be run simultaneously. The position of the bedded and unbedded pens were alternated between replicates.

The pigs, from a specific-pathogen-free Yorkshire herd, had been weaned at about 28 days of age and then housed in raised weaner-decks with metal flooring. The animal had had no exposure to straw before the experiment began. They were moved at 36-47 days of age into the experimental pens (on a Monday; Day 0) and given 7 days to adapt. Behaviour was then recorded in two ways. Detailed records were made by direct observation on 4 of the 5 weekdays during the animals' second week in the pens (Days 7-11), and video recording was used to monitor overall activity patterns during a 72-h period beginning after the direct observations had been completed. The pigs were removed on Day 14 and the pens were cleaned for the next groups. Pigs were weighed individually at the beginning and end of the test, and all feed added to the feeders or remaining after the test was weighed. One replicate was replaced because it had abnormally low feed intake and weight gains owing to a problem in the water supply.

When the pigs were first moved into the pens, one pen was supplied with $3 \mathrm{~kg}$ of oat straw distributed over the floor. Each morning at 09:00 h, faeces and soiled straw were removed from the pens, and a similar quantity of fresh straw was provided. Dim light (two 25-W bulbs) was provided from 18:00 to 06:00 
$\mathrm{h}$, and bright light (three additional $100 \mathrm{~W}$ bulbs) from 06:00 to 18:00 $\mathrm{h}$ daily. Pigs were marked with crayon for easy individual identification.

For the direct behavioural observations, each group of three pigs was observed for four 20-min periods per day on 4 days. Two observation periods took place in the morning (09:00-11:00 h) when the straw was fresh, and two took place in the afternoon (13:00-15:00 h) when the straw was less novel. In each 20-min period an observer recorded one group of three pigs, and another observer simultaneously recorded the other group of the same replicate. The observers then switched groups for the next 20-mm period.

During each 20-min period, an audible signal sounded every $30 \mathrm{~s}$ and the observer recorded, for each of the three pigs in the group, whether any of the activities listed in Table 1 had been performed at any time in that $30 \mathrm{~s}$. This yielded "one-zero" scores (Martin and Bateson, 1986) with a maximum value of 40 for each pig and each activity in each 20 -min period.

\section{TABLE 1}

Behavioural categories recorded by direct observation in Experiment 1

\begin{tabular}{|cll|}
\hline 1 & Lying & Head in feeders, or gathering or chewing food \\
2 & Feeding & Mouth in contact with nipple drinker \\
3 & Drinking & $\begin{array}{l}\text { Back-and-forward movement of the snout over floor, walls, straw, etc., but not } \\
\text { pen-mates, for } 2 \text { s or more }\end{array}$ \\
4 & Rooting environment & Rooting action in contact with any part of a pen-mate, for 2 s or more \\
5 & Rooting pen-mates & $\begin{array}{l}\text { Chewing action, applied to walls, fixtures, etc., scored if the object was seen in } \\
\text { the pig's mouth }\end{array}$ \\
6 & Chewing environment & Apparently non-aggressive chewing of any part of pen-mate (ears, tail, hooves) \\
7 & Chewing pen-mates & Apparently aggressive bite directed at a pen-mate, not necessarily connecting \\
8 & Chewing straw & Placing front hooves on the back of a standing pen-mate \\
9 & Biting & Running with bouncing movement \\
10 & Mounting & Rapid upward movement of the head, usually begun with the head lowered, \\
11 & Scampering & directed at a pen-mate, not necessarily connecting \\
12 & Butting & Backward scraping movement with one front hoof \\
13 & Pawing & Supported by front legs and hindquarters \\
14 & Sitting &
\end{tabular}

The $72 \mathrm{~h}$ video recording used instantaneous sampling at 10-min intervals to determine diurnal patterns of overall activity. An external timing device activated the video recorder every $10 \mathrm{~min}$. On playback, the observer noted the behaviour of each pig using the three mutually exclusive categories of lying, feeding (head in feeder), or active (standing or sitting but not feeding).

\section{Experiment 2}

The second experiment studied pigs aged about 10 weeks, housed in groups of eight in floor pens, with or without a small amount of straw available from a rack. Four replicates of a cross-over design were used, each involving two groups of eight pigs. Within a replicate the 16 pigs were obtained from three or four litters and were allocated to the two groups so that the groups had a similar sex ratio and average body weight. The two groups were housed in adjacent pens, $1.8 \mathrm{~m} \times 4.3 \mathrm{~m}$, with a solid concrete floor and solid steel partitions. Each pen contained a two-hole feeder with feed ad libitum, two nipple drinkers and a straw rack. The rack was 0.6-m long, located midway on the long side of the pen, and was 
supported on the pen partition about $0.6 \mathrm{~m}$ above the floor; 6-mm vertical steel rods spaced $6 \mathrm{~cm}$ apart retained the straw along the exposed face of the rack. Lighting was provided by six 100-W bulbs from 06:00 to 22:00 $\mathrm{h}$ and one 100-W bulb from 22:00 to 06:00 $\mathrm{h}$. The animals had had no exposure to straw before the experiment began.

Pigs remained in the pens for 3 weeks. The first week allowed the animals to adapt to the pen and no straw was offered. During the second week one group was given $5 \mathrm{~g}$ of barley straw daily from the straw rack at about 13:50 h (10 min. before direct observations began in the afternoon), while the other group received none. The group which received straw in the second week had none in the third week, and vice versa.

Direct observations and video recordings were made in each of Weeks 2 and 3 . For the direct observations, an observer watched each group during four 15-min periods, separated by 15-min rest periods, in the morning (09:00-11:00 h) and four in the afternoon (14:00-16:00 h) on 4 days each week. Each day two different pigs in each group were selected as focal animals, so that all eight pigs in each group were observed on 1 of the 4 days of observation In each 15-min period, the observer recorded all activities (described below) performed by each of the two focal animals in each 30 -s period. This gave one-zero scores ranging from 0 to 30 for a 15 -min period. Single values for each morning and afternoon were obtained by summing over the four respective periods. The two pens were always observed simultaneously by two observers who switched pens at the end of each 15-min period.

Time-lapse video recording was used to monitor patterns of overall activity throughout the day. A video camera recorded one frame every $10 \mathrm{~min}$ for 4 days of observation in each of Weeks 2 and 3 . On playback, an observer counted the number of pigs in each pen that were lying, feeding, or active, as in the first experiment.

Behavioural Categories 1-11 from Experiment 1 (Table 1) were used in the direct observations, but with the following changes. Both rooting and chewing of the environment (Categories 4 and 6 ) were subdivided into those activities directed towards: (i) the floor; (ii) the walls and fixtures. Biting (Category 9) was scored as occurring at either of the following locations: (i) near the feeder, when one pig displaced or seemed to attempt to displace another; (ii) not near the feeder. To improve detection of the major social activities, the focal animals were also scored for all instances of receiving (as well as performing) the following: rooting pen-mates, chewing pen-mates, biting (near the feeder), biting (not near the feeder), and mounting. As a measure of overall activity specifically during the direct observations, pigs were scored as active whenever they were not lying down. Butting, which appeared to occur in both aggressive and play contexts, was not scored. Two minor non-social categories (pawing and sitting) were not scored.

\section{Statistical methods}

Data from direct observations were combined (over the various 15- and 20-min observation periods) into (i) morning and (ii) afternoon observations for each animal on each day. Similarly, video recording data were summed over each 2 -h period from midnight to midnight. These combined values reduced variability and more closely approximated the normal distribution.

Analyses of variance were applied to pen means (not individual pigs) because animals in the same pen influence each others' behaviour. Preliminary analysis of the direct observations showed a significant interaction of treatment (straw or no straw) and time of day (morning or afternoon) for many of the behavioural categories, especially in Experiment 2 where provision of fresh straw in the afternoon had a clear impact on behaviour. Therefore, morning and afternoon observations were analysed separately. Experiment 1 used a randomized block analysis based on pen means with ten replicates and two 
treatments, the treatment effect being tested against the interaction with one and nine degrees of freedom. Experiment 2 used a cross-over analysis based on mean values per pen in each week. The treatment effect was tested against a pooled error term with one and eleven degrees of freedom. Because of some heterogeneity of variance, the data were also analysed after logarithmic transformation. As this produced little difference in interpretation, the results are presented in the original scale.

Fig. 1. The percentage of observations in which pigs were scored as feeding (above) or active but not feeding (below), based on time-lapse video recording in Experiment 1. Pigs were housed with straw bedding (solid line) or without (broken line). Daytime lighting extended from 06:00 to 18:00 $\mathrm{h}$. Pens were cleaned and straw replenished at 09:00 $\mathrm{h}$ (shown by arrow). Results are means of 2-h periods. Lying (not shown) consisted of all observations not scored as active or feeding.

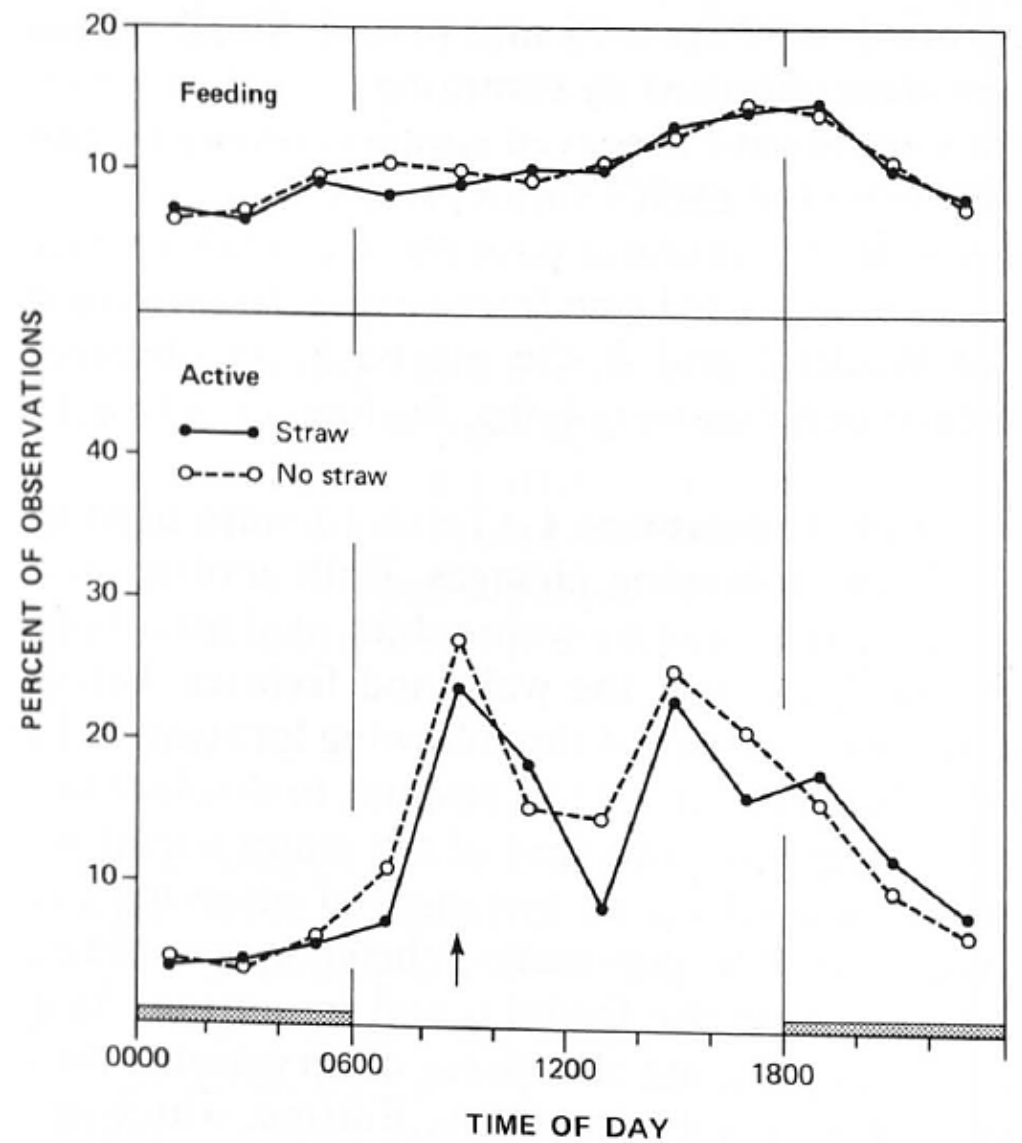

\section{RESULTS}

\section{Experiment 1}

In Experiment 1, the presence of straw bedding had no identifiable influence on overall activity as detected by time-lapse video recording (Fig. 1). Pigs in both treatments showed a peak of activity at about 09:00 $\mathrm{h}$ when the pens were cleaned, and another peak in the afternoon about $3 \mathrm{~h}$ before the dark period. In both treatments, feeding increased gradually during most of the day until the end of daytime lighting. Analysis of variance showed no differences $(P>0.05)$ between treatments and no treatment $\times$ time interaction in these measures. 
TABLE 2

Mean scores per pig $^{1}$ for behavioural categories recorded by direct observation in morning and afternoon periods in Experiment 1 (fresh straw provided as bedding in the morning)

\begin{tabular}{|c|c|c|c|c|c|c|c|c|}
\hline \multirow[t]{2}{*}{ Behaviour } & \multicolumn{4}{|c|}{ Morning } & \multicolumn{4}{|c|}{ Afternoon } \\
\hline & $\begin{array}{l}\text { With } \\
\text { straw }\end{array}$ & $\begin{array}{l}\text { Without } \\
\text { straw }\end{array}$ & SEM & $P$ & $\begin{array}{l}\text { With } \\
\text { straw }\end{array}$ & $\begin{array}{c}\text { Without } \\
\text { straw }\end{array}$ & SEM & $P$ \\
\hline \multicolumn{9}{|c|}{ (a) Higher scores with straw than without (in morning) } \\
\hline Feeding & 15.3 & 11.9 & 0.93 & $<0.05$ & 12.7 & 11.3 & 1.17 & NS \\
\hline Drinking & 4.4 & 2.3 & 0.50 & $<0.05$ & 2.9 & 2.9 & 0.25 & NS \\
\hline Chewing straw & 21.0 & 0.0 & ${ }^{2}$ & ${ }^{2}$ & 5.5 & 0.0 & ${ }^{2}$ & ${ }^{2}$ \\
\hline Sitting & 1.9 & 0.7 & 0.27 & $<0.05$ & 1.6 & 0.7 & 0.29 & $<0.10$ \\
\hline Pawing & 1.0 & 0.2 & 0.17 & $<0.01$ & 0.6 & 0.3 & 0.17 & NS \\
\hline \multicolumn{9}{|c|}{ (b) Lower scores with straw than without (in morning) } \\
\hline Lying & 38.0 & 48.1 & 2.27 & $<0.05$ & 56.4 & 52.8 & 3.02 & NS \\
\hline Rooting pen-mates & 0.4 & 1.2 & 0.26 & $<0.10$ & 0.5 & 1.2 & 0.21 & $<0.05$ \\
\hline Chewing pen-mates & 0.2 & 0.7 & 0.12 & $<0.05$ & 0.2 & 0.5 & 0.10 & $<0.05$ \\
\hline Chewing environment & 0.2 & 0.7 & 0.21 & NS & 0.3 & 0.6 & 0.13 & $<0.10$ \\
\hline \multicolumn{9}{|c|}{ (c) Similar scores with and without straw } \\
\hline Rooting environment & 19.6 & 20.7 & 2.90 & NS & 7.5 & 13.2 & 3.00 & NS \\
\hline Scampering & 0.5 & 0.8 & 0.25 & NS & 0.4 & 0.7 & 0.13 & NS \\
\hline Mounting & 0.1 & 0.1 & 0.05 & NS & 0.1 & 0.2 & 0.06 & NS \\
\hline Biting & 1.1 & 1.1 & 0.18 & NS & 0.7 & 1.1 & 0.21 & NS \\
\hline Butting & 2.5 & 2.5 & 0.55 & NS & 1.3 & 1.9 & 0.29 & NS \\
\hline
\end{tabular}

${ }^{1}$ Results are means of one-zero scores (Martin and Bateson, 1986) with a maximum possible value of 80.

${ }^{2}$ Value omitted because statistical comparison is inappropriate.

NS, not significant.

Direct observations showed that pigs with straw were somewhat more active than the controls in the morning when the straw was fresh, as indicated by their lower scores for lying (Table 2 (b)). Pigs with straw also performed more $(P<0.05)$ feeding, drinking, sitting and pawing than pigs without straw, in the morning (Table 2(a)). Bedded pigs were seen chewing straw in an average of 21 of the 8030 -s periods during morning observations.

Despite their higher level of activity in the mornings, pigs with straw performed less rooting and chewing of their pen-mates, and tended to chew the environment less (Table 2 (b)). The presence of straw had no significant effect on scores for other social activities (biting, butting, mounting) nor for scampering or rooting the environment (Table 2 (c)).

\section{Experiment 2}

In Experiment 2, provision of straw in the rack did not influence the total level of pig activity (as detected by time-lapse video recording), but it did influence the diurnal pattern. Both with and without straw, pigs were more active in the afternoon than in the morning (Fig. 2). Pigs given straw (about 13:50 h) were significantly more active $(P<0.05)$ in the 2-h periods of 12:00-14:00 $\mathrm{h}$ and 14:00-16:00 $\mathrm{h}$ than pigs without straw. At all other times, pigs with straw tended to be less active, the difference between treatments being statistically significant for 20:00-22:00 h $(P<0.05)$. Overall, pigs were active (but not feeding) in $15.3 \%$ of observations with straw and in $15.2 \%$ without straw. Analysis of variance showed no 
difference between treatments but a highly significant time $\times$ treatment interaction in active time over the $24 \mathrm{~h}(P<0.001)$. There was also considerable diurnal variation in feeding $(P<0.01)$, with a gradual increase during most of the daytime light periods (Fig. 2). The provision of straw had no discernible impact on the feeding pattern.

Fig. 2. The percentage of observations in which pigs were scored as feeding (above) or active but not feeding (below), based on time-lapse video recording in Experiment 2. Pigs received straw in a rack (solid line) or no straw (broken line) about 13:50 h each day (shown by arrow). Daytime lighting extended from 06:00 to 22:00 h. Results are means of 2-h periods. Lying (not shown) consisted of all observations not scored as active or feeding.

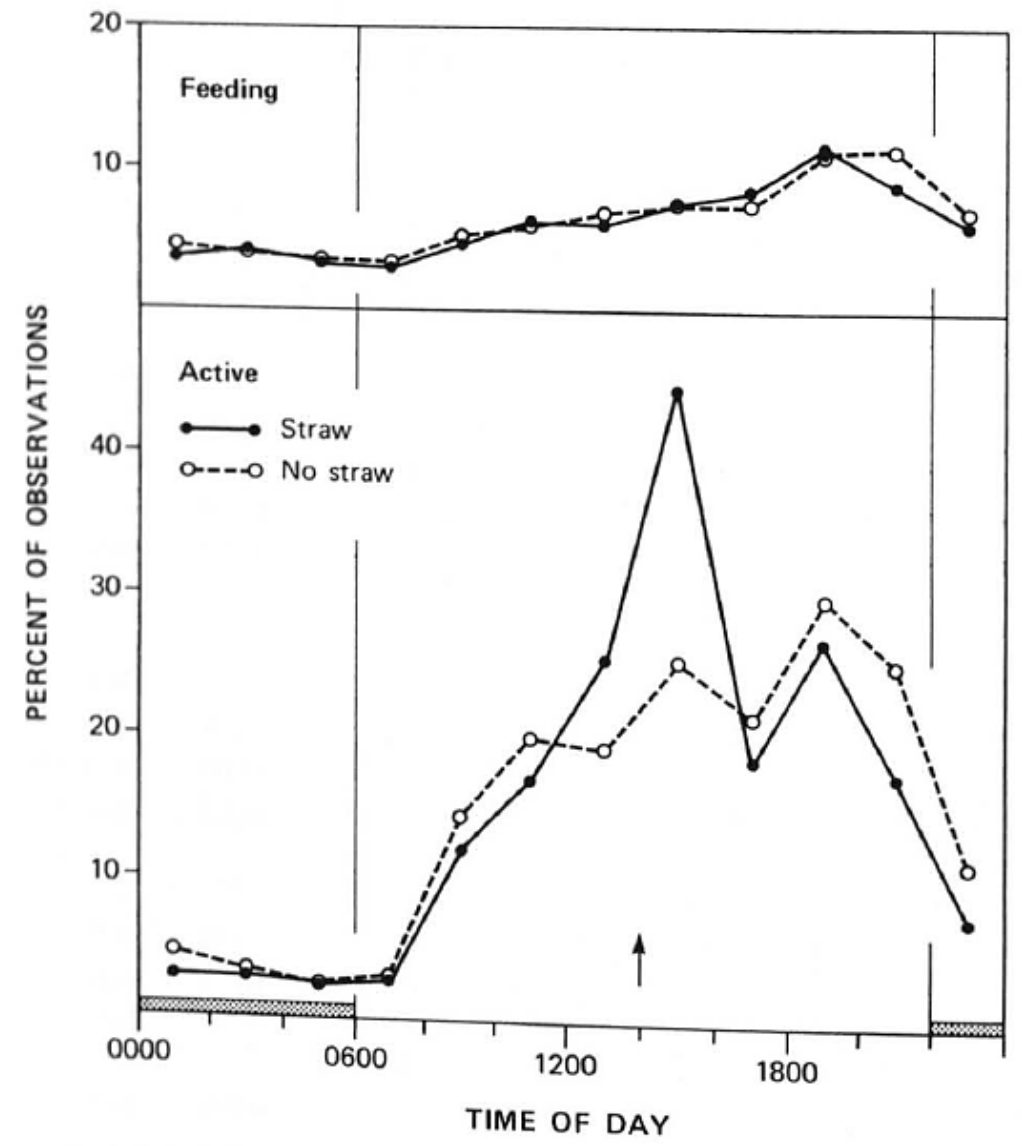

Most of the behavioural categories recorded by direct observation showed higher levels of activity in the afternoon than in the morning (Table 3), corresponding to the higher levels of overall activity in the afternoon shown by video recording (Fig. 2). In afternoon observations, pigs with straw were significantly more active and rooted the floor more (Table 3(a)). In addition, they scampered more and both performed and received more biting (not near the feeder). Despite being more active, pigs with straw rooted penmates and chewed the walls significantly less, and they received less rooting and chewing (Table 3 (b)). Straw had no apparent effect on other behaviour including feeding, drinking, and aggressive biting near the feeder (Table 3 (c)).

At the time of the morning observations, the straw offered on the previous day had been completely removed from the rack and was often dirty and trampled. These morning observations showed no differences between the straw and no-straw treatments in any behavioural category (Table 3). 
TABLE 3

Mean scores per pig $^{1}$ for behavioural categories recorded by direct observation in morning and afternoon periods in Experiment 2 (fresh straw provided in a rack in the afternoon)

\begin{tabular}{|c|c|c|c|c|c|c|c|c|}
\hline \multirow[t]{2}{*}{ Behaviour } & \multicolumn{4}{|c|}{ Morning } & \multicolumn{4}{|c|}{ Afternoon } \\
\hline & $\begin{array}{l}\text { With } \\
\text { straw }\end{array}$ & $\begin{array}{l}\text { Without } \\
\text { straw }\end{array}$ & SEM & $P$ & $\begin{array}{l}\text { With } \\
\text { straw }\end{array}$ & $\begin{array}{c}\text { Without } \\
\text { straw }\end{array}$ & SEM & $P$ \\
\hline \multicolumn{9}{|c|}{ (a) Higher scores with straw than without (in afternoon) } \\
\hline Active & 21.0 & 20.3 & 2.59 & NS & 83.1 & 44.7 & 3.28 & $<0.001$ \\
\hline Rooting floor & 7.1 & 6.3 & 0.95 & NS & 56.5 & 17.0 & 2.64 & $<0.001$ \\
\hline Chewing straw & 2.0 & 0.0 & ${ }_{-}^{2}$ & ${ }^{2}$ & 47.6 & 0.0 & ${ }^{2}$ & ${ }^{2}$ \\
\hline Biting $^{3}$ & 0.7 & 0.6 & 0.14 & NS & 4.5 & 2.6 & 0.39 & $<0.01$ \\
\hline Receive biting ${ }^{3}$ & 0.3 & 0.4 & 0.10 & NS & 4.1 & 1.8 & 0.39 & $<0.01$ \\
\hline Scampering & 0.1 & 0.0 & 0.07 & NS & 2.8 & 0.8 & 0.52 & $<0.05$ \\
\hline \multicolumn{9}{|c|}{ (b) Lower scores with straw than without (in afternoon) } \\
\hline Lying & 104.7 & 105.0 & 2.05 & NS & 49.2 & 83.3 & 3.58 & $<0.001$ \\
\hline Rooting pen-mates & 3.4 & 3.9 & 0.61 & NS & 2.7 & 4.9 & 0.70 & $<0.05$ \\
\hline Receive rooting & 3.0 & 3.4 & 0.54 & NS & 2.4 & 5.2 & 0.39 & $<0.001$ \\
\hline Chewing pen-mates & 1.1 & 1.6 & 0.45 & NS & 1.3 & 2.1 & 0.34 & NS \\
\hline Receive chewing & 1.1 & 2.5 & 0.72 & NS & 0.9 & 2.5 & 0.44 & $<0.05$ \\
\hline Chewing walls & 0.2 & 0.5 & 0.16 & NS & 0.5 & 1.7 & 0.32 & $<0.05$ \\
\hline \multicolumn{9}{|c|}{ (c) Similar scores with and without straw } \\
\hline Feeding & 8.5 & 7.2 & 1.13 & NS & 12.4 & 13.2 & 0.97 & NS \\
\hline Drinking & 1.3 & 1.3 & 0.23 & NS & 3.8 & 3.2 & 0.34 & NS \\
\hline Biting $^{4}$ & 0.7 & 0.8 & 0.13 & NS & 0.7 & 1.5 & 0.32 & NS \\
\hline Receive biting ${ }^{4}$ & 0.4 & 0.5 & 0.15 & NS & 0.7 & 0.8 & 0.14 & NS \\
\hline Mounting & 0.1 & 0.1 & 0.05 & NS & 0.7 & 0.3 & 0.14 & NS \\
\hline Receive mounting & 0.1 & 0.1 & 0.05 & NS & 0.7 & 0.5 & 0.16 & NS \\
\hline Chewing floor & 1.1 & 0.9 & 0.40 & NS & 0.8 & 0.7 & 0.47 & NS \\
\hline Rooting walls & 3.1 & 1.7 & 1.06 & NS & 5.7 & 5.5 & 0.82 & NS \\
\hline
\end{tabular}

${ }^{1}$ Results are means of one-zero scores (Martin and Bateson, 1986) with a maximum possible value of 120.

${ }^{2}$ Value omitted because statistical comparison is inappropriate.

${ }^{3}$ Not near feeder.

${ }^{4}$ Near feeder.

NS, not significant.

\section{DISCUSSION}

If temperature is constant and moderate, pigs exposed to $12 \mathrm{~h}$ of light per day are generally much more active during the light phase, and show a gradual increase in feeding and other activities during the daylight hours (Ingram et al., 1980). Our results followed these trends, but with additional activity peaks corresponding to daily maintenance activities and provision of straw. These and other results (e.g. Dantzer and Mailhé, 1972; Ingram et al., 1980; Fraser, 1985) show how easily the pig's typical diurnal activity pattern is influenced by human activities or other factors (see also Algers, 1984).

The provision of straw had two clear effects in these studies. Firstly, although not influencing the total amount of time the pigs were active, daily provision of straw in a rack did influence the timing of their activity. Specifically, pigs with straw were more active in the $2 \mathrm{~h}$ or so when the straw was fresh, and 
correspondingly less active at other times. This increased activity involved more scampering, biting, and rooting on the floor, with much of this last behaviour directed towards straw on the floor. In Experiment 1 , with ample straw available at all times, the provision of fresh straw had little impact on the daily pattern of activity. The larger effect seen in Experiment 2 was presumably because the supply of straw had been completely exhausted (eaten or trampled) when the new straw arrived.

Secondly, when straw was fresh, it became a major focus for chewing and rooting, and these activities were directed less at pen-mates. In Experiment 1, pigs housed on straw bedding did less rooting and chewing of pen-mates in both morning and afternoon observation periods. In Experiment 2, the difference between treatments was clear in the afternoon but had disappeared by the following morning, when fresh straw was no longer available. However, given the low level of such behaviour in the morning observation periods, it seems likely that provision of straw in racks did produce a net reduction in mutual rooting and chewing over the day taken as a whole.

In contrast to rooting and chewing of pen-mates, other social activities (biting near the feeder, biting not near the feeder, mounting) were not at all reduced by the provision of straw. In fact, in Experiment 2, aggressive biting in a non-feeding context was increased immediately after straw was provided. This increase in biting was associated with a general increase in activity, and often involved disputes over access to the fresh straw. Such disputes were usually brief and seemed relatively harmless, as the pigs were largely preoccupied by the straw.

Pigs in Experiment 1 generally spent more time feeding than those in Experiment 2 (compare Figs. 1 and 2). As this trend was seen both with and without straw, the difference was probably not a result of the manner in which straw was presented. Rather, the greater competition for access to the feeder in Experiment 2 (with eight pigs per pen instead of three) may simply have encouraged the animals to eat more efficiently.

Our findings with growing pigs closely parallel those of Schouten (1986) who studied suckling and newly weaned piglets housed with or without straw. As in our results, Schouten found that straw: (i) decreased the amount of chewing and rooting directed by piglets to their pen-mates; (ii) bad little influence on other categories such as eating and agonistic behaviour; (iii) had some influence on the diurnal pattern, but not the total amount, of overall activity. These results are also generally consistent with those of van Putten and Dammers (1976), van Putten (1980), Buré (1981), Algers (1984), and Ruiterkamp (1986).

Under certain husbandry conditions, straw has potential benefits which should not be underestimated. For example, straw can improve the thermal comfort (and probably survival) of piglets in cool conditions (Stephens, 1971); it bas complex effects on the behaviour and perhaps the productivity of confined sows on restricted diets (Fraser, 1975; Sambraus and Schunke, 1982); and the rearing of suckling litters in large pens with straw is reported to make the animals less restless later in life (Schouten, 1986). Straw can also give animals better control over their micro-environment, and it thus makes possible a wider latitude in barn temperature. However, our results indicate that for growing pigs with adequate space, feed, and thermal comfort, the one significant function of straw is to provide a stimulus and outlet for exploratory and manipulative activities involving the snout and mouth, which could otherwise be directed to pen-mates and might contribute to more significant problems such as tail-biting. Where the use of straw is impractical, the provision of other suitable objects for chewing and rooting might achieve the same result. 


\section{ACKNOWLEDGEMENTS}

We are grateful to S. Fournier, D. Alves, M. Murray, H. Descrombecque and R.A. Allen for assisting in the observations, and to the staff of the ARC pig unit for their cooperation.

\section{REFERENCES}

Algers, B., 1984. Early weaning and cage rearing of piglets; Influence on behaviour. Zentralbl. Veterinärmed., Reihe A, 31: 14-24.

Buré, R.G., 1981. Animal well-being and housing systems for piglets. In: W. Sybesma (Editor), The Welfare of Pigs. Martinus Nijhoff, The Hague, pp. 198-207.

Dantzer, R. and Mailhé, G., 1972. Mise en évidence d'un rythme dans le comportement d'activité motrice du porcelet. C.R. Soc. Biol., 166: 456-459.

Edwards, S.A. and Furniss, S.J., 1988. The effects of straw in crated farrowing systems on peri-partal behaviour of sows and piglets. Br. Vet. J., 144: 139-146.

Fraser, D., 1975. The effect of straw on the behaviour of sows in tether stalls. Anim. Prod., 21: 59-68.

Fraser, D., 1985. Selection of bedded and unbedded areas by pigs in relation to environmental temperature and behaviour. Appl. Anim. Behav. Sci., 14: 117-126.

Ingram, D.L., Walters, D.E. and Legge, K.F., 1980. Variations in motor activity and in food and water intake over $24 \mathrm{~h}$ periods in pigs. J. Agric. Sci., 95: 371-380.

Martin, P. and Bateson, P., 1986. Measuring Behaviour. Cambridge University Press, Cambridge, 200 pp.

Marx, D. and Mertz, R., 1989. Ethologische Wahlversuche mit frühabgesetzten Ferkeln während der Haltung in Buchten mit unterschiedlicher Anwendung von Stroh. I. Mitteilung: Auswirkungen verschiedener anwendungen des Strohes und unterschiedlicher Bodenbeschaffenheit bei einheitlicher Flächengrosse. Dtsch. Tierärztl. Wochenschr., 96: 20-26.

Müller, J., Nabholz, A., van Putten, G. and Sambraus, H.H., 1979. Tierschutzbestimmungen für die Schweinehaltung. In: G.M. Teutsch, E. von Loeper, G. Martin and J. MUller (Editors), Intensivhaltung von Nutztieren aus ethischer rechtlicher und ethologischer Sicht. Birkhäuser, Basel, pp. 123-194.

Ruiterkamp, W.A., 1986. Een vergelijkend onderzoek naar welzijn bij mestvarkens. Tijdschr. Diergeneeskd., III: 520-528.

Sambraus, H.H. and Schunke, B., 1982. Verhaltensstörungen bei Zuchtsauen im Kastenstand. Wiener Tierärztl. Monatsschr., 69: 200-208.

Schouten, W.G.P., 1986. Rearing conditions and behaviour in pigs. Ph.D. Thesis, Agricultural University, Wageningen, $151 \mathrm{pp}$.

Stephens, D.B., 1971. The metabolic rates of newborn pigs in relation to floor insulation and ambient temperature. Anim. Prod., 13: 303-313.

Van Putten, G., 1980. Objective observations on the behaviour of fattening pigs. Anim. Reg. Stud., 3: 105-118. 
Van Putten, G. and Dammers, J., 1976. A comparative study of the well-being of piglets reared conventionally and in cages. Appl. Anim. Ethol., 2: 339-356. 